\title{
Bazı Entomopatojenlerin Orosanga japonica (Melichar, 1898) (Hemiptera: Ricaniidae) Üzerindeki Öldürücü Etkilerinin Belirlenmesi
}

\author{
Temel GÖKTÜRK* \\ Artvin Çruh Üniversitesi, Orman Fakültesi, Orman Mühendisliği Bölümü, Artvin, TÜRKIYYE
}

\begin{tabular}{l}
\hline \multicolumn{1}{c}{ Geliş Tarihi/Received: $17.07 .2020 \quad$ Kabul Tarihi/Accepted: 18.10 .2020} \\
\hline ORCID ID \\
(D) orcid.org/0000-0003-4064-4225 \\
"Sorumlu Yazar/Corresponding Author: temel.gokturk@gmail.com
\end{tabular}

Öz: Bu çalışmada, Orosanga japonica'nın (Melichar, 1898) (Hemiptera: Ricaniidae) nimf ve erginlerine karşı laboratuvar ve arazi koşullarında Beauveria bassiana, Metarhizium anisopliae, Bacillus thuringiensis entomopatojenleri ve Nimbecidine ${ }^{\circledR}$ organik insektisit uygulanarak öldürücü etkileri belirlenmeye çalışılmıştır. Çalışma, 2020 yılı Haziran ve Temmuz aylarında Kemalpaşa, Arhavi ve Artvin'de 4 tekerrürlü olarak yürütülmüștür. Tül kafesler içerisine alınan nimf ve erginlerin üzerine entomopatojenler ve Nimbecidine püskürtülerek 2 günde bir kontrol edilerek ölen bireyler not edilmiştir. Çalışma sonucunda tüm entomopatojenlerin ve Nimbecidinenin $O$. japonica'nın hem nimf hemde erginlerine belirli oranlarda etki ettiğ görülmüştür. Laboratuvarda kontrollü koşullarında uygulanan organik insektisit ve entomopatojenler sonucunda ölüm oranları nimflerde \% 73-94 ve erginlerde \% 18.5-60 arasında tespit edilmiştir. Arazi koşullarında O. japonica nimf ve erginlerine karş1 uygulanan organik insektisit ve entomopatojenler sonucunda ölüm oranları nimflerde $\%$ 50.5-75, erginlerde $\%$ 11-50.5 olarak gerçekleşmiştir. Hem laboratuvarda hem de saha koşullarında, en yüksek ölüm oranı değerleri ergin ve nimflerde Nimbecidine uygulamalarında görülmüsstür. Beauveria bassiana, Metarhizium anisopliae, Bacillus thuringiensis karışımı ile oluşturulan preparat $(\mathrm{BMB})$ da başarılı bulunmuştur.

Anahtar Kelimeler: Orosanga japonica, Beauveria bassiana, Metarhizium anisopliae, Bacillus thuringiensis, Nimbecidine

\section{Determination of the Lethal Effects of Some Entomopathogens on Orosanga japonica (Melichar, 1898) (Hemiptera: Ricaniidae)}

\begin{abstract}
In this study, the lethal effects of Beauveria bassiana, Metarhizium anisopliae, Bacillus thuringiensis entomopathogens, and Nimbecidine ${ }^{\circledR}$ organic insecticide, against Orosanga japonica (Melichar, 1898) (Hemiptera: Ricaniidae) nymphs and adults, were tried to be determined under laboratory and field conditions. The study was conducted in Kemalpaşa, Arhavi and Artvin with 4 replications in June and July, 2020. Entomopathogens and Nimbecidine sprayed on the nymphs and adults taken in tulle cages and the individuals who died were checked every 2 days. As a result of the study, it was observed that all entomopathogens and Nimbecidine had certain effects on both nymphs and adults of O. japonica. As a result of organic insecticides and entomopathogens applied in controlled conditions in the laboratory, mortality rates were determined between $73-94 \%$ in nymphs and $18.5-60 \%$ in adults. As a result of organic insecticides and entomopathogens applied against $O$. japonica nymphs and adults under field conditions, mortality rates were $50.5-75 \%$ in nymphs and $11-50.5 \%$ in adults. Both in the laboratory and field conditions, the highest mortality rates were seen in Nimbecidine application in adults and nymphs. The preparation (BMB) formed with a mixture of Beauveria bassiana, Metarhizium anisopliae, Bacillus thuringiensis was also found successful.
\end{abstract}

Keywords: Orosanga japonica, Beauveria bassiana, Metarhizium anisopliae, Bacillus thuringiensis, Nimbecidine 


\section{Giriș}

Hemiptera takımı içerisinde yer alan Ricaniidae türleri dünyada 45 'in üzerinde cins ve 450 tür ile temsil edilen küçük bir familyadır (Chou ve ark., 1985; Xu ve ark., 2006; Fletcher, 2008; Bu ve ark., 2010). Bu familya üyeleri daha çok tropik bölgelerde yayılış gösterse de yanlızca Ricania cinsi Palaearktik bölgede görülebilmektedir (Demir, 2009).

Ricania türleri içerisinde Orosanga japonica (Melichar, 1898) (Homoptera: Ricaniidae) (Yalanc1 kelebek) dünyanın bir çok ülkesinde önemli bir zararlı böcek türü olarak kabul edilmektedir (Gnezdilov, 2009; Bu ve ark., 2010). Bulgaristan, Çin, Gürcistan, Hindistan, Japonya, Ukrayna, Rusya, Tayvan ve Türkiye yayılış gösterdiği ülkelerdir (Avidzba ve Bobokhidze, 1982; Nast, 1987; Urban ve Cryan, 2007; Demir, 2009; Gjonov, 2011; Göktürk ve Aksu, 2014). O. japonica'nın Türkiye'ye Doğu Karadeniz Bölgesi'ndeki sınır komşusu Gürcistan'dan bulaşık bitki materyalleri ile geldiği düşünülmektedir. $O$. japonica, Türkiye'de ilk tespit edildiği 2006 yılından bu yana Artvin ve Rize illerinin sahil ilçelerinde yoğun olmakla beraber, Trabzon, Giresun ve Ordu illerinin sahil ilçelerinde de münferit olarak görülmektedir (Göktürk ve Mihlı, 2015). O. japonica 2018 y1lına kadar $R$. simulans olarak biliniyor iken, 2018 yılında yapılan DNA testleri sonrası bölgede yayılış gösteren türün $O$. japonica (=Ricania japaonica) olduğu tescillenmiştir. Türkiye için istilacı yabancı tür konumunda olan $O$. japonica'nın, Doğu Karadeniz Bölgesi dışında Bartın, Düzce ve İstanbul'da da yayılış gösterdiği rapor edilmiştir (Demir, 2009; Ak ve ark., 2015; Göktürk ve Aksu, 2014; Göktürk ve Mihlı, 2015; Gokturk ve ark., 2018; Oztemiz, 2018, Yıldız ve ark., 2018).

O. japonica erginlerinin pronotum şekli üçgen ve başı düzdür. Kanatlarda yoğun enine damarlar bulunmaktadır. Ön kanatlarının üzerinde enine, açık gri renkte iki bant bulunmakta, arka kanatlar ise şeffaf görünümdedir. Erginlerin gövdesi 8-11 mm uzunluğunda olup kanat açıklıkları 13-14 mm arasında değişen, kahverengi tonlarında kelebek görünümündedir. Bundan dolayı yöre halkı tarafindan "vampir kelebek" olarak adlandırılmaktadırlar. Erginler yavaş hareket etselerde rahatsız edildiklerinde sıçrayıp uçabilmektedirler. Nimflerinin vücutları sarı, açık gri ve üzerinde kahverengi suşları vardır. Beş nimf dönemine sahip olan $O$. japonica'nın son dönem nimfleri $4.5 \mathrm{~mm}$ boyunda ve $3 \mathrm{~mm}$ eninde olup, abdomenin sonunda vücut boyundan daha uzun, beyaz renkte ve uzunca mumsu iplikçikler olmasından dolayı tavus kuşuna benzemektedir. Yılda bir generasyona sahip olan $O$. japonica'nın iklim şartlarına bağlı olarak Mayıs ayının ortasında nimflerini, Temmuz başında erginlerini görmek mümkündür. Ağustos ayında yumurtalarını taze bitki filizlerine ve ince dalların daha çok alt kısımlarına ince yarıklar açarak bırakarak kışı yumurta döneminde geçirmektedir (Göktürk ve Aksu, 2014).

Orosanga japonica, bir çok meyve ağaçında, meyvelerde, sebzelerde, süs bitkilerinde, çalılar ve yabani otlarda zarar yapan polifag bir türdür (Demir, 2009). Doğu Karadeniz Bölgesi'nde en çok kivi, üzüm, incir, keçisakalı, eğrelti, ısırgan otu, ortanca, mürver, böğürtlen bitkilerini tercih etmektedir (Göktürk ve Mihlı, 2015). $O$. japonica'nın hem nimf hem de erginleri konukçu bitkilerinin özsuyunu emerek zarar vermektedir. Sıcak ve nemli havalarda böceğin bitkide yaptığ1 zarar artabilmektedir. Öz su emerek yaptığ 1 direkt zararın yanında, bazı önemli bitki patojeni fungusların (Cylindrocarpon sp., Fusarium sp. ve Pestalotiopsis quepinii) vektörlüğünü de yapmaktadır (Eken ve ark., 2013).

Dünyada bu zararlının mücadelesinde yaygın olarak geniş spektrumlu sentetik ilaçlar kullanılmaktadır (Wojciechowska ve ark., 2016). Böceğin zarar yaptığı alan Doğu Karadeniz Bölgesi'nde organik çay üretimi yapıldığından mücadele yöntemleri sınırlı kalmıştır. Türe has ruhsatlandırılmış insektisitin olmayışı ve aynı zamanda alanda kimyasalların kullanımının yasak olması türün mücadelesinde alternatif yöntemlerin araştırılmasını zorunlu kılmıştır. Bu yöntemlerden biri de entomopatojenlerin kullanıldığ 1 biyolojik insektisitler olup bu insektisitlerin dünyadaki kullanımları hergeçen gün artmaktadır (Kim ve ark., 2001). Bu grup içerisinde yer alan entomopatojenik mantarlar, potansiyel biyolojik kontrol ajanları olarak eklembacaklıların doğal düşmanlarıdır. Mantarlar içerisinde 700'den fazla entomopatojen tür bulunmaktadır (Wraight ve ark., 2001; Vestergaard ve ark., 2003; Roy ve ark., 2006; Sandhu ve ark., 2012). Bunun yanında Beauveria bassiana, Bacillus thurigiensis, Isaria farinose, I. fumosorosea, Lecanicillium spp. ve Metarhizium anisopliae gibi bakteriyel entomopatojenler böcek popülasyonlarının baskı altına alınmasında önemli bir rol oynamaktadır (Zimmermann, 2008; Gurulingappa ve ark., 2011). Bu bakteriyal entomopatojenler içerisinde ençok bilinen ve kullanılan Bacillus thuringiensis var. kurstaki'dir (Lacey ve ark., 2001). Entomopatojen funguslar özellikle sokucu emici ağız yapısına sahip böcekler ile mücadelesinde kullanılan ve böcekleri kutikula yolu ile enfekte eden etmenlerdir. Entomopatojenik mantarlardan çoğu Metarhizium, Beauveria, Trichoderma, Verticillium, Nomuraea, Entomophtora ve Neozygite cinslerine ait olup bir 
çok böcek türü üzerinde etkilidir (Deshpande, 1999). Beauveria bassiana ve Metarhizium anisopalia entomopatojenlerinin birçok zararlı böcek türüne karş1 biyolojik savaşta kullanıldığ1 rapor edilmiş ve bunların ticari preparatları geliştirilerek piyasaya sunulmuştur (Wraight ve ark., 2001; Copping, 2004).

O. japonica'nın Doğu Karadeniz Bölgesi'nde görülmesinden günümüze kadar geçen sürede mücadelesine yönelik birçok bilimsel çalışma yapılmıştır. Guclu ve ark. (2010), Lecanicillium muscarium kullanılarak; Ak ve ark. (2013), Azadirachtin ve Spinosad kullanarak; Ak ve ark. (2014), Conidiobolus coronatus kullanarak; Göktürk ve Mihlı (2015), 1şık tuzakları ve sarı renkli yapışkan tuzaklarını kullanarak; Gokturk ve ark. (2018), 10 entomopatojenik bakteri ve mantar kullanarak bu zararlılara karşı kontrol üzerine bir çalışma yürütmüşlerdir. Sezen ve ark. (2014) $O$. japonica'dan 16 bakteri izolatı elde etmiş ve bu izolatlardan Pseudomonas sp. ve Bacillus thuringiensis potansiyel biyolojik kontrol ajanı olarak değerli olabileceğini vurgulamıştır.

$\mathrm{Bu}$ çalışmada, Kemalpaşa ve Arhavi (Artvin) tarım alanlarında nimf ve ergin dönemindeki $O$. japonica'lara laboratuvar ve arazi koşullarında Beauveria bassiana, Metarhizium anisopliae, Bacillus thuringiensis entomopatojenleri ve Nimbecidine ${ }^{\circledR}$ organik insektisit uygulanarak öldürücü etkileri belirlenmeye çalışılmıştır.

\section{Materyal ve Yöntem}

$\mathrm{Bu}$ çalışmanın materyalini; O. japonica'nın 3. dönem nimfleri, erginleri, taze kivi sürgünleri, fasülye fideleri, Japon şemsiyesi, tül kafesler, el pompas1, Beauveria bassiana, Metarhizium anisopliae, Bacillus thuringiensis entomopatojenleri, yayıcı-yapıştırıcı olarak Activator $^{\circledR}$ ve organik insektisit olan Nimbecidine ${ }^{\circledR}$ oluşturmaktadır. Beauveria bassiana, Metarhizium anisopliae, Bacillus thuringiensis entomopatojen izolatları ve yayıcı yapıştırıcı olarak kullanılan Activator $^{\circledR}$ Gen-Orb LTD.'den (Ankara) temin edilmiştir. Nimbecidine ${ }^{\circledR}$ ise ticari olarak faaliyet gösteren tarım ilaç satış bayisinden satın alınmıştır. Entomopatojen solüsyonlarının içine yayıcı ve yapıştırıcı olarak $50 \mathrm{~mL}$ de Activator $^{\circledR}$ ilave edilmiştir. Nimbecidine, Neem ağacı tohumlarında bulunan Azadirachtin içeren neem yağı bazlı bitkisel kökenli bir insektisittir. Nimbecidine; böcekleri uzaklaştırıcı (repellent), beslemeyi önleyici (anti feedant), yumurta bırakmayı önleyici, kısırlaştırıcı, büyüme ve gelişmeyi önleyici, öldürücü ve dezenfektan özellikleri ile etki etmektedir. Nimbecidine ticari adi ile satilan bu organik ilacın aktif maddesi $0.3 \mathrm{~g} \mathrm{~L}^{-1}$ Azadirachtin olup, formulasyonu EC (Emülsiye olabilen konsantre)'dir.

Çalışmalar, 2020 yılında böceklerin de biyolojileri dikkate alınarak Haziran ve Temmuz ayları arasında $O$. japonica'nın nimf ve erginlerine karşı hem laboratuvar hemde arazi koşullarında 4 tekerrürlü olarak gerçekleştirilmiştir.

O. japonica nimfleri, 2020 Mayıs ayının son haftasında Kemalpaşa (Artvin) ilçesinde eğrelti otları (Pteridium aquilinum)'ndan, erginler ise 2020 Temmuz ayında Arhavi ilçesinde kivi ağacı (Actinidia deliciosa) üzerinden toplanarak plastik bidonlara konulmuş ve laboratuvara getirilmiştir. Laboratuvarda önceden saksılara ekilmiş fasulye fidanlarının üzerine 20'șer adet bırakılarak tüllerle örtülmüştür. Bacillus thuringiensis var. kurstaki $109 \mathrm{Cfu} \mathrm{mL}^{-1}$, Buaveria bassiana $108 \mathrm{Cfu} \mathrm{mL}^{-1}$, Metharihizium anisopalia 1010 Cfu $\mathrm{mL}^{-1}$ konsantrasyonları nimfler üzerine ayrı ayrı ve Bacillus thuringiensis var. kurstaki + Metharihizium anisopalia + Buaveria bassiana karışım şeklinde (BMB) uygulanmıştır. Ayrıca pozitif kontrol olarak Nimbecidine ${ }^{\circledR}$ ve kontrol olarak ta steril saf su kullanılmıştır. B. bassiana, $M$. anisopliae, $B$. thuringiensis entomopatojenleri ve Nimbecidine, $50 \mathrm{~mL} 10 \mathrm{~L}^{-1}$ su şeklinde hazırlanarak el pompası ile böceklerin üzerine püskürtülerek denenmiştir. Konrtol amaçlı bir kafese de saf steril su uygulanmıştır. Laboratuvarda; entomopatojen uygulanan $O$. japonica 3 . dönem nimfleri 8 gün boyunca $26 \pm 1^{\circ} \mathrm{C}$ ve $\% 70 \pm 5$ bağıl nemde inkübe edilmiştir.

Arazi denemelerinde, nimflerin yoğun bulunduğu fasulye ve böğürtlen bitkileri seçilmiştir. Üzerlerinde en az 20 adet nimf olan bitkilerin üzerleri tül $(30$ x $50 \mathrm{~cm})$ ile kapatılmış ve tül üzerinden el pompası ile entomopatojen ve insektisit uygulaması yapılmıştır. Aynı şekilde kivi sürgünleri üzerinde yer alan erginlerde sürgünle birlikte tül içerisine alınarak preparat uygulaması gerçekleştirilmiştir. Arazi uygulamaları, ortalama sıcaklığın gece $19.2^{\circ} \mathrm{C}$ ile gündüz $29.5^{\circ} \mathrm{C}$ arasında değiştiği yaz aylarında, bağıl nem ortalaması \% 75 ve yağış miktarı $12.5 \mathrm{~mm}$ olduğunda gerçekleştirilmiştir. Tüm uygulamalarda, tül içerisine alınan bitkilerin her iki günde bir kontrolleri yapılarak ölen nimf ve ergin sayıları not edilmiştir.

Uygulanan entomopatjen ve organik insektisitin nimf ve ergin ölümü üzerindeki etkilerini belirlemek için 8 günlük takip süresi boyunca günlere göre ölüm oranları dikkate alınarak tek yönlü ANOVA, istatistiksel analizler için de SPSS 15.0 yazılımı kullanılmıştır. 


\section{Bulgular ve Tartışma}

O. japonica nimf ve erginlerine karşı uygulanan organik insektisit ve entomopatojenler hem laboratuvar hem de arazi uygulamalarında belirli oranlarda etkili olmuştur. Laboratuvar koşullarında yapılan uygulamalarda ölüm oranları nimflerde $\%$ 73-94, erginlerde \% 18.5-60 olarak tespit edilmiştir. En yüksek ölüm oranı Nimbecidinede erginlerde \% 60, nimflerde \% 94.0 olarak belirlenmiştir. Entomopatojen uygulamaları sonucu görülen ölüm oranları $M$. anisopliae'de erginlerde $\% \quad 36$, nimflerde $\% \quad 80, \quad B$. thuringiensis'te erginlerde $\% 20$, nimflerde $\% 73$, B. bassiana'da erginlerde $\%$ 18.5, nimflerde $\% 74$ ve tüm entomopatojenlerin karışımında (BMB) erginlerde $\% 45.5$, nimflerde $\% 85$ olarak belirlenmiştir (Tablo 1, Şekil 1 ve 2). Ölüm oranları incelendiğinde tüm entomopatojenleri karıştırılarak yapılan uygulamanın tek tek entomopatojen uygulamasından daha iyi sonuç verdiği görülmektedir.

Tablo 1. Nimbecidine ve entomopatojenlerin laboratuvar ortamında $O$. japonica'nın nimf ve erginleri üzerindeki öldürücü etki değerleri*

\begin{tabular}{|c|c|c|c|c|}
\hline \multirow[b]{2}{*}{ Uygulanan preparatın adı } & \multicolumn{2}{|c|}{ Nimf dönemi } & \multicolumn{2}{|c|}{ Ergin dönemi } \\
\hline & $\begin{array}{c}\text { Ölen birey } \\
\text { say1s1 }\end{array}$ & $\begin{array}{l}\text { Ölüm oran1 } \\
(\%)\end{array}$ & $\begin{array}{c}\text { Ölen birey } \\
\text { say1sı }\end{array}$ & $\begin{array}{l}\text { Ölüm oran1 } \\
(\%)\end{array}$ \\
\hline Beauveria bassiana & $14.8^{\mathrm{d}}$ & 74 & $3.7^{\mathrm{d}}$ & 18.5 \\
\hline Metarhizium anisopliae & $16.0^{\mathrm{c}}$ & 80 & $7.2^{\mathrm{c}}$ & 36.0 \\
\hline Bacillus thuringiensis & $14.6^{\mathrm{d}}$ & 73 & $4.0^{\mathrm{d}}$ & 20.0 \\
\hline B. bassiana + M. anisopliae $+B$. thurigiensis & $17.0^{\mathrm{b}}$ & 85 & $9.1^{\mathrm{b}}$ & 45.5 \\
\hline Nimbecidine ${ }^{\circledR}$ & $18.8^{\mathrm{a}}$ & 94 & $12.0^{\mathrm{a}}$ & 60.0 \\
\hline
\end{tabular}

*: Aynı sütunda aynı harfle gösterilen ölüm ortalamaları arasındaki farklılık istatistiki açıdan önemsizdir.

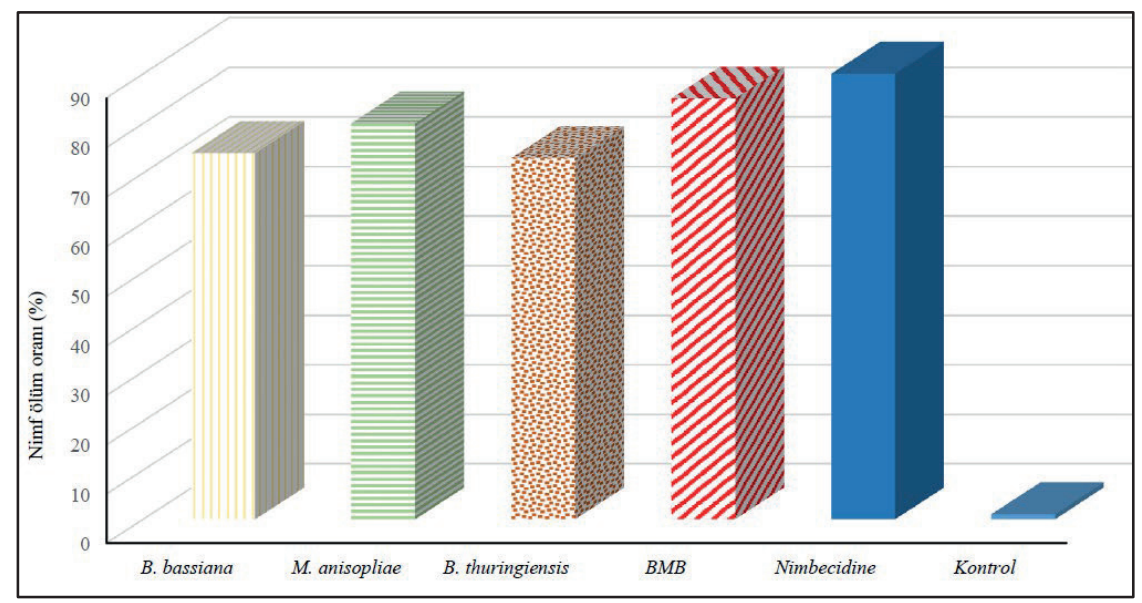

Şekil 1. O. japonica nimflerine karşı laboratuvar koşullarında yapılan uygulamalarda görülen ölüm oranları

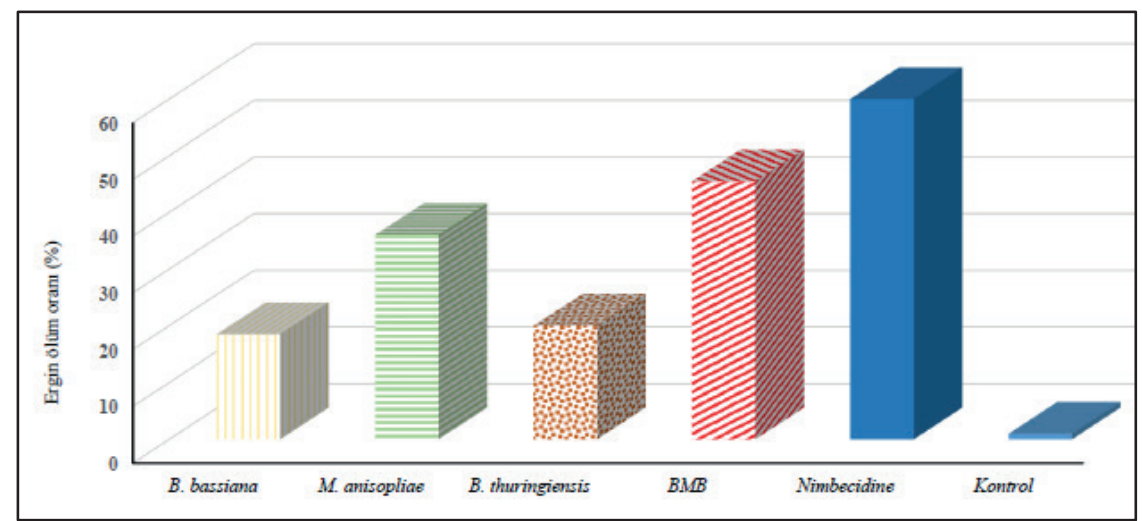

Şekil 2. O. japonica erginlerine karş̧ laboratuvar koşullarında yapılan uygulamalarda görülen ölüm oranları 
Yapılan gözlemlerde ölümlerin $M$. anisopliae uygulamasında 2. günde, $B$. thuringiensis ve $B$. bassiana uygulamalarında da 4 . günde görülmeye başlamıştır. Entomopatojenlerin hepsinin olduğu karışım uygulamasında ise ölümler 2. günde başlamıştır (Şekil 3). Arazi uygulamalarında da benzer sonuçlar gözlenmiş ancak ölüm oranları oranları daha düşük bulunmuştur (Şekil 4). Laboratuvar uygulamalarında $M$. anisopliae uygulanan $O$. japonica nimflerinde ölümler 4. ve 6 . gün yoğun olurken, diğer entomopatojenlerde 6 . ve 8. gün ölüm oranlarında artış görülmüştür (Şekil 3). Laboratuvar uygulamalarında da erginler içinde benzer sonuçlar görülmüştür (Şekil 4).
Laboratuvar uygulamalarında, Nimbecidine ve entomopatojen uygulamaları sonuçunda her iki günde bir yapılan sayımlar sonucu elde edilen nimflerin ölüm oranları incelendiğinde $O$. japonica nimflerinin \% 58.8, erginlerinin \% 33.8'nin ikinci gün öldüğü görülmüştür. Ak ve ark. (2013), Spinosad'la laboratuvar koşullarında yaptıkları mücadele denemelerinde sipinosadın $35 \mathrm{ml} 100$ $\mathrm{L}^{-1}$ 'lik dozunun etkili doz olduğu ve \% 71.2-78.7 oranında biyolojik etki gösterdiğini belirtilmektedir. Yaptığımız bu çalışmada pozitif kontrol olarak kullanılan Nimbecidine'nin uygulama dozu arttırılırsa daha fazla ölüm oranının ortaya çıkması muhtemeldir.

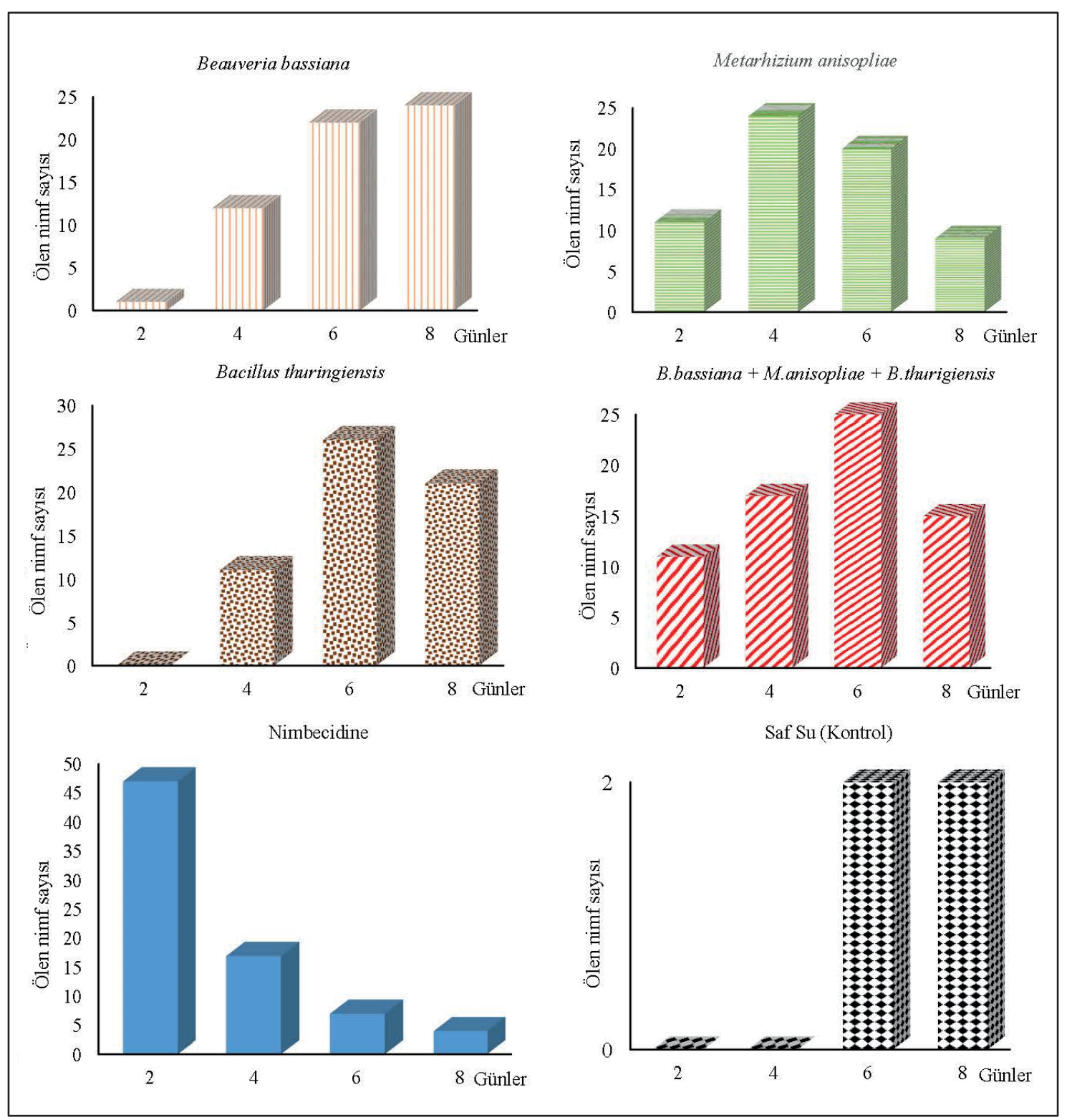

Şekil 3. Laboratuvar denemelerinde yapılan uygulamalar sonucu gözlemlenen nimf ölüm sayıları 


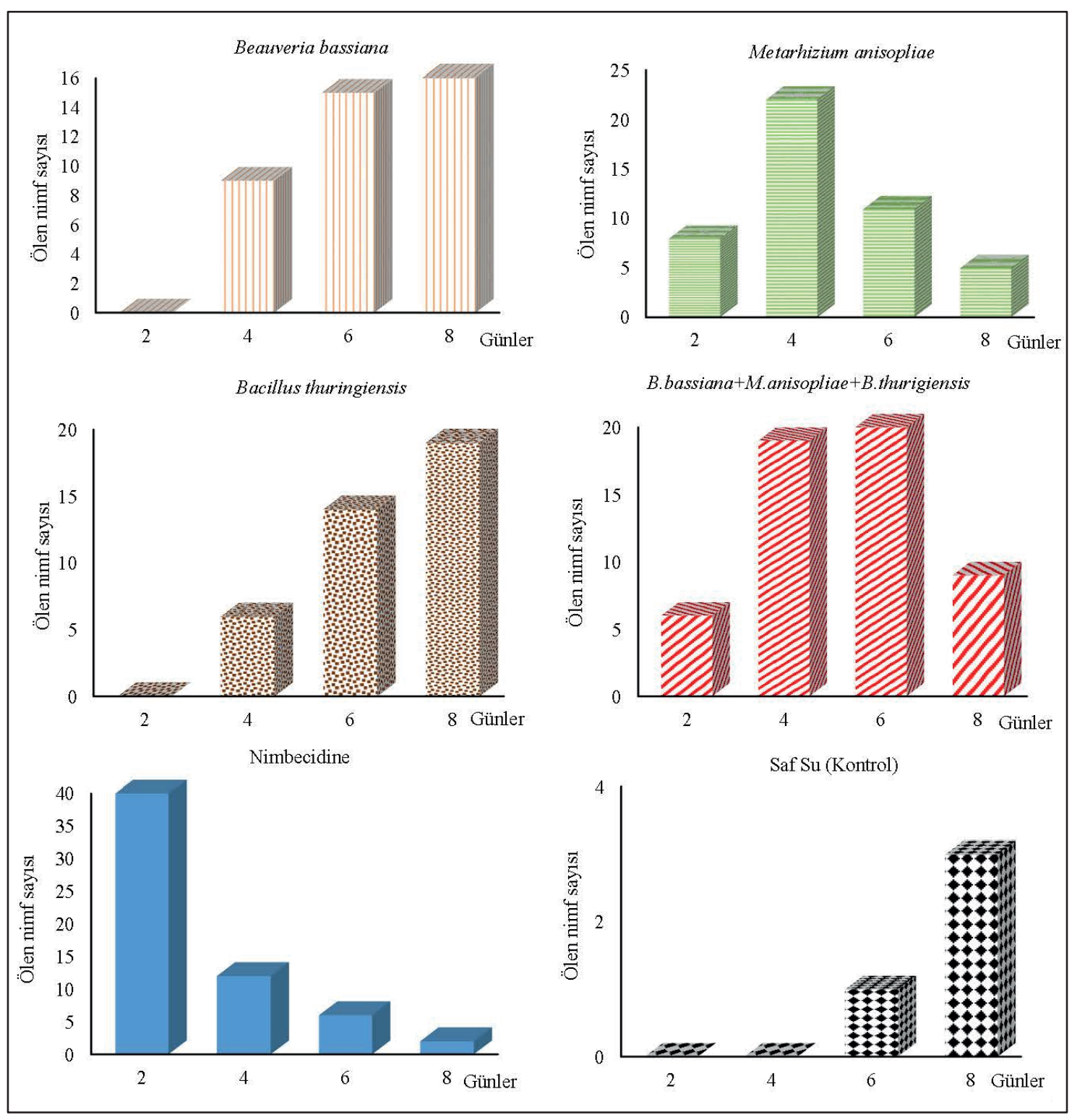

Şekil 4. Laboratuvar denemelerinde yapılan uygulamalar sonucu gözlemlenen ergin ölüm sayıları

Arazi koșullarında $O$. japonica nimf ve erginlerine karşı uygulanan organik insektisit ve entomopatojenler sonucunda ölüm oranları nimflerde $\% 49$ ve $\% 75$, erginlerde $\% 11$ ve $\% 50.5$ olarak tespit edilmiştir. En yüksek ölüm oranı Nimbecidinede erginlerde \% 50.5, nimflerde \% 75 olarak belirlenmiştir. Entomopatojen uygulamaları sonucu görülen ölüm oranları $M$. anisopliae'de erginlerde $\% \quad 20$, nimflerde $\% \quad 59.5, \quad B$. thuringiensis'te erginlerde $\% 13$, nimflerde $\% 49$, B. bassiana'da erginlerde $\% 11$, nimflerde $\% 50.5$ ve tüm entomopatojenlerin karışımında (BMB) erginlerde $\%$ 28.5, nimflerde $\% 66$ olarak belirlenmiştir. Ölüm oranları incelendiğinde tüm entomopatojenleri karıştırılarak yapılan uygulamanin tek tek entomopatojen uygulamasından daha iyi sonuç verdiği görülmektedir (Tablo 2, Şekil 5 ve 6).

O. japonica nimflerinin \% 50'sinin, erginlerinin de \% 20’sinin arazi koşullarında ikinci gün Nimbecidine uygulamalarında öldüğü gözlemlenmiştir. Yapılan arzi gözlemlerinde ölümlerin $M$. anisopliae ve tüm entomopatojen karışımınının uygulamasında 2. günde, $B$. thuringiensis ve B. bassiana uygulamalarında da 4 . günde görülmeye başlamıştır. Arazi uygulamalarında $M$. anisopliae uygulanan $O$. japonica nimflerinde ve erginlerinde ölümler 4 . ve 6. gün yoğun olurken, diğer entomopatojenlerde 6 . ve 8 . gün ölüm oranlarında artış görülmüştür (Şekil 7 ve 8$)$. 
GÖKTÜRK

Tablo 2. Organik insektisit ve entomopatojenlerin arazi şartlarında $O$. japonica'nın nimf ve erginleri üzerindeki öldürücü etki değerleri*

\begin{tabular}{lcccc}
\hline \multirow{2}{*}{ Uygulanan preparatın ad1 } & \multicolumn{2}{c}{ Nimf dönemi } & \multicolumn{2}{c}{ Ergin dönemi } \\
\cline { 2 - 5 } & $\begin{array}{c}\text { Ölen birey } \\
\text { Sayıs }\end{array}$ & Ölüm oran1 & Ölen birey & Ölüm oran1 \\
& $10.1^{\mathrm{d}}$ & 50.5 & $2.2^{\mathrm{d}}$ & 11.0 \\
\hline Beauveria bassiana & $11.9^{\mathrm{c}}$ & 59.5 & $4.0^{\mathrm{c}}$ & 20.0 \\
Metarhizium anisopliae & $9.8^{\mathrm{d}}$ & 49.0 & $2.6^{\mathrm{d}}$ & 13.0 \\
Bacillus thuringiensis & $13.2^{\mathrm{b}}$ & 66.0 & $5.7^{\mathrm{b}}$ & 28.5 \\
B. bassiana + M. anisopliae+B. thurigiensis & $15.0^{\mathrm{a}}$ & 75.0 & $10.1^{\mathrm{a}}$ & 50.5 \\
Nimbecidine ${ }^{\circledR}$ & &
\end{tabular}

*: Aynı sütunda aynı harfle gösterilen ölüm ortalamaları arasındaki farklılık istatistiki açıdan önemsizdir.

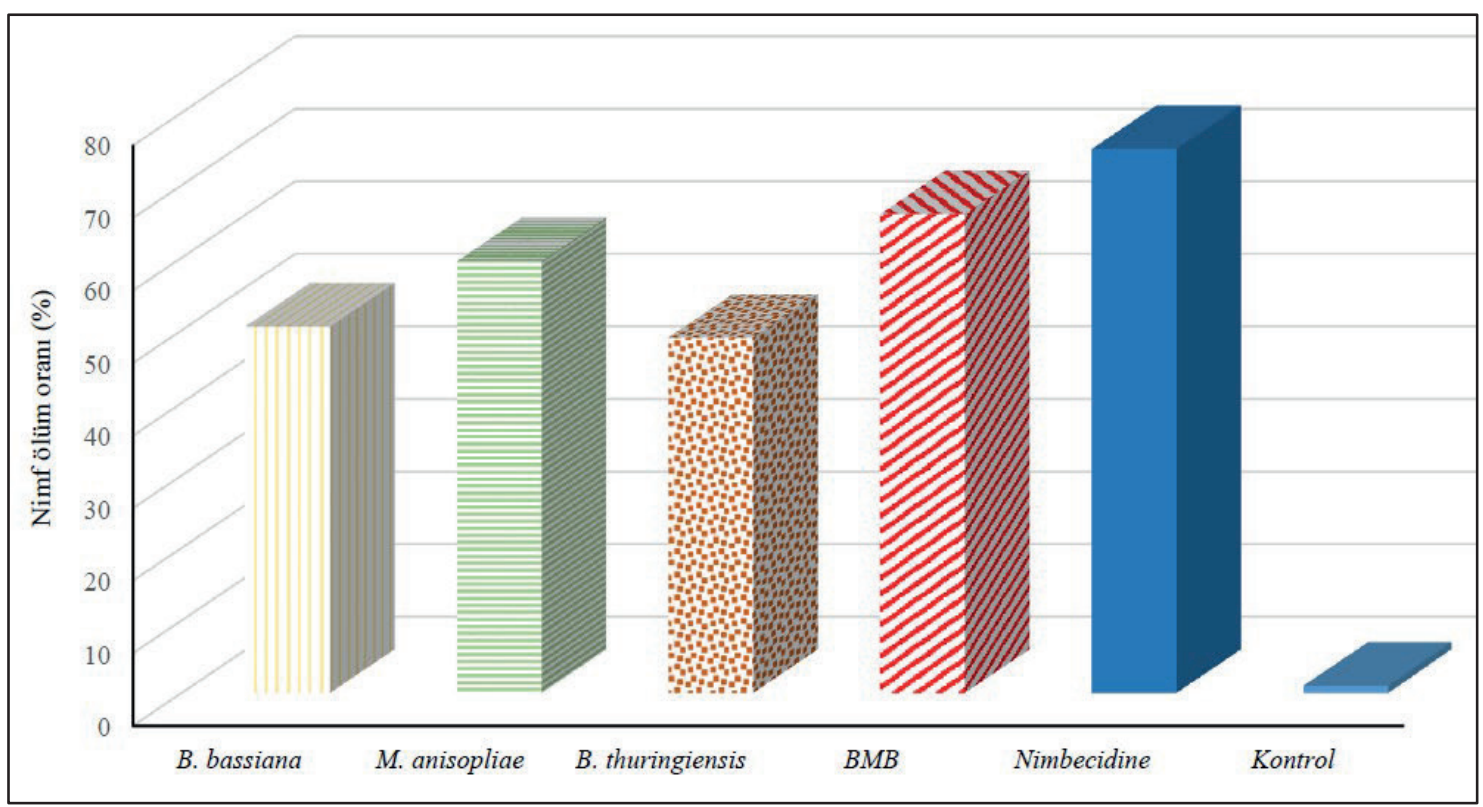

Şekil 5. O. japonica nimflerine karşı arazi koşullarında yapılan uygulamalarda görülen ölüm oranları

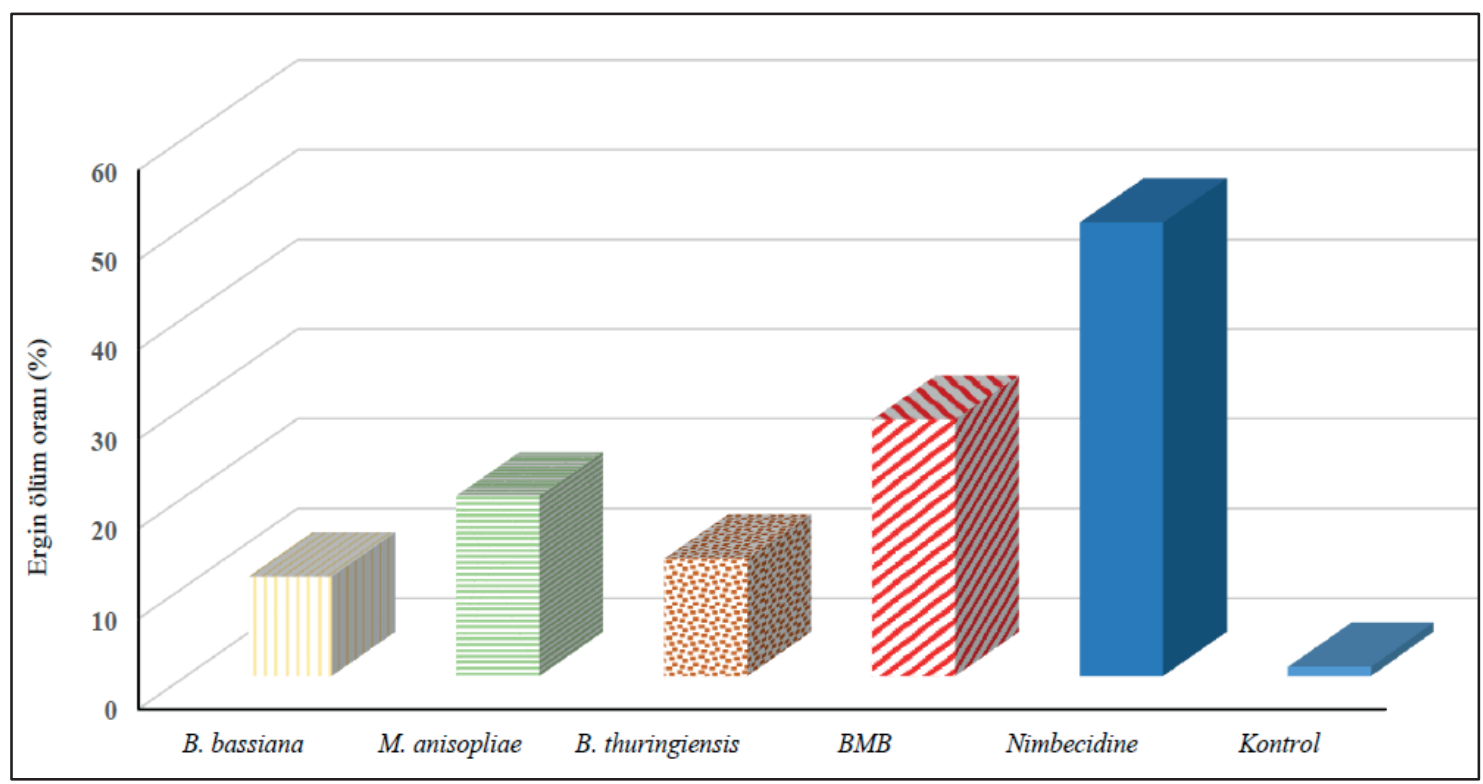

Şekil 6. O. japonica erginlerine karşı arazi koşullarında yapılan uygulamalarda görülen ölüm oranları 


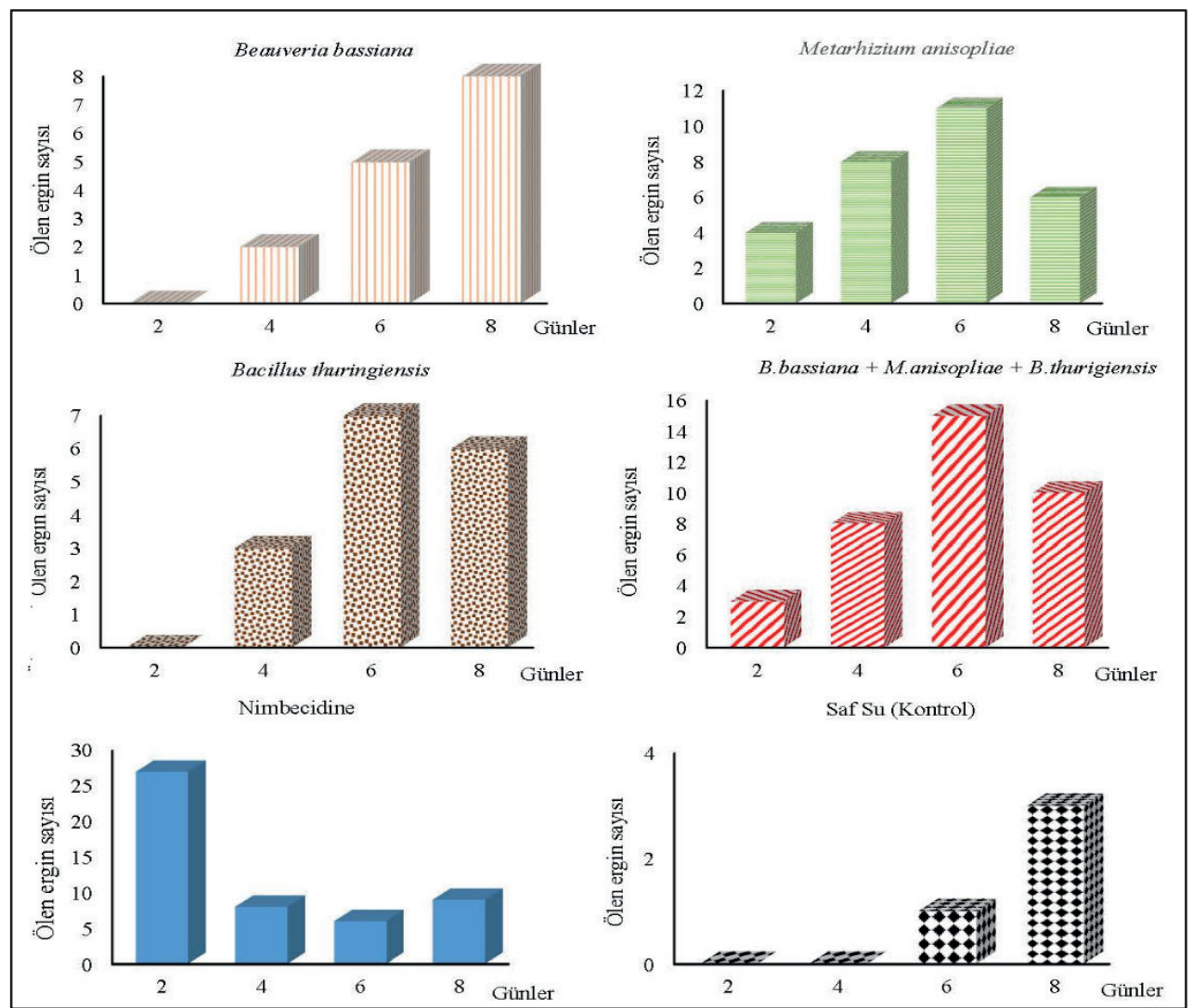

Şekil 7. Arazi denemelerinde yapılan uygulamalar sonucu gözlemlenen nimf ölüm sayıları

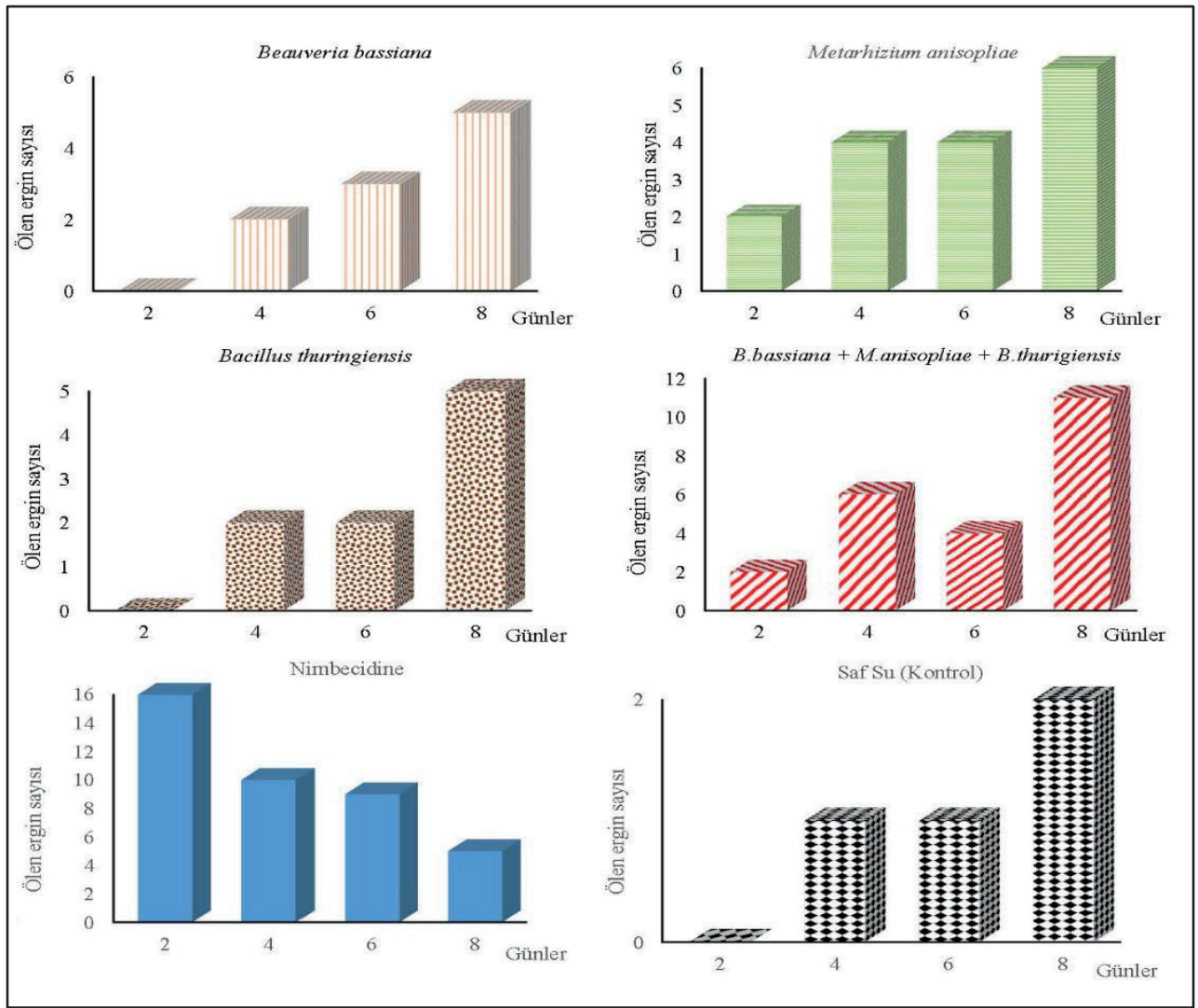

Şekil 8. Arazi denemelerinde yapılan uygulamalar sonucu gözlemlenen ergin ölüm sayıları 
Zararlı böceklerin mücadelesine yönelik entomopatojenlerin kullanımı konusunda yapılmış birçok çalışma mevcuttur (Lacey ve ark., 2001; Vestergaard ve ark., 2003, Copping, 2004; Khachatourians ve Sohail, 2008; Ak ve ark., 2013, 2014). O. japonica'ya karşı biyolojik pestisit uygulamalarına yönelik yapılan çalışmalar ise oldukça sınırlıdır. Arazide kivi bitkisinde ve laboratuvarda çay yaprakları üzerinde nimflerle yapılan bir çalışmada 107 conidia $\mathrm{mL}^{-1}$ lik bir dozda Lecanicillium muscarium (Petch)'un 6 izolatınının $\% \quad 50.95-74.76$ oranında öldürücü etkisi belirlenmiştir (Guclu ve ark., 2010). Ak ve ark. (2014), bu türe karşı başka bir entomopatojenik mantar olan Conidiobolus coronatus'u hem laboratuvar hem de arazi koşullarında denemiş ve \% 100 başarılı sonuçlar aldıklarını bildirmişlerdir. Yaptığımız bu çalışmada uygulamalarda hiçbir preparatta \% 100 ölüm oranına rastlanamamıştır. Alev (2014), O. japonica'dan 16 bakteri suşu izole etmiş ve bunlardan Bacillus thuringiensis'in erginler üzerinde \% 86 öldürücü etki ile en yüksek öldürücü aktiviteyi gösterdiğini belirtmiştir. Uygulamalarımızda, Bacillus thuringiensis'in erginler üzerinde \% 20, nimfler üzerinde ise $\% 73$ öldürücü etkisi olduğu görülmüş̧tür. Gokturk ve ark. (2018), O. japonica'ya karşı gerçekleştirdikleri entomopatojen uygulamalarında nimflere karşı Brevibacillus brevis, Bacillus thuringiensis, Bacillus thuringiensis subsp. kenyae, Bacillus thuringiensis subsp. kurstakii, Bacillus subtilis, Pseudomonas chlororaphis, Bacillus sphaericus, Beauveria bassiana. Bacillus thuringiensis subsp. kenyae, Brevibacillus brevis ve Bacillus sphaericus'un; erginlere karşı da Bacillus thuringiensis subsp. kurstakii, Pseudomonas chlororaphi ve Brevibacillus brevis'in en etkili olduğunu belirtmektedir. Yapılan uygulamalarda nimf ölüm oranları \% 19.58-42.08 arasında ve ergin ölüm oranları da \% 6-18 arasında bulunmuştur. Bu çalışmada ise ölüm oranları, laboratuvar koşullarında nimflerde \% 73-94, erginlerde \% 1860 arasında bulunurken, arazi koşullarında ise ölüm oranları nimflerde \% 49-75, erginlerde ise \% 1150.5 arasında olduğu görülmüştür.

\section{Sonuçlar}

O. japonica'ya karşı test edilen tüm preparatlar hem laboratuvar hem de arazi koșullarında az veya çok oranda öldürücü etki göstermiştir. Çalışma sonuçları irdelendiğinde, nimflere karşı yapılan uygulamaların daha etkili olduğu görülmektedir. Çalışmada kullanılan entomopatojenlerin tümüne sahip olan karışımın nimf ve erginlere karşı daha etkili olduğu belirlenmiştir. Bunu sırasıly M. anasophila, B. bassiana, B. thuringiensis izlemiştir.
Sonuç olarak, Nimbecidine organik insektisitin O. japonica nimf ve erginlerinde etkili olduğu görülmüştür. Ayrıca, çalışmada kullanılan $M$. anisopliae, $B$. thuringiensis, B. bassiana ve yayıc1 yapıştırıcı (Activator ${ }^{\circledR}$ ) karışımı ile hazırlanan preparatın (BMB) O. japonica'nın nimfleriyle mücadelede kullanılabileceğini kanısına da varılmıştır.

\section{Kaynaklar}

Ak, K., Eken, C., Guclu, S., Genc, T., Sekban, R., 2014. Laboratory and field evaluation of the entomopathogenic fungus, Conidiobolus coronatus for controlling Ricania simulans (Walker, 1851) (Hemiptera: Ricaniidae). Egyptian Journal of Biological Pest Control, 24(2): 455-459.

Ak, K., Güçlü, Ş., Eken, C., Sekban, R., 2015. Türkiye için yeni bir zararlı Ricania simulans (Walker, 1851) (Hemiptera: Ricaniidae). Türkiye Entomoloji Dergisi, 39(2): 179-186.

Ak, K., Güçlü, Ş., Sekban, R., 2013. Doğu Karadeniz Bölgesi'nde yeni bir zararl1 Ricania simulans (Walker, 1851) (Hemiptera: Ricaniidae)'a karş1 azadirachtin ve spinosad etki maddeli biyopestisitlerin etkinliklerinin belirlenmesi. Tarım Bilimleri Araştırma Dergisi, 6 (1): 10-14.

Alev, F., 2014. Ricania simulans'1n bakteriyal mücadele etmeninin araștırılması. Yüksek lisans tezi, Karadeniz Teknik Üniversitesi Fen Bilimleri Enstitüsü, Trabzon.

Avidzba, N.S., Bobokhidze, Z.M., 1982. Biophenology of the Japanese Leafhopper. Zashchita Rastenii, No: 6.

Bu, C.P., Lariviere, M.C., Liang, A.P., 2010. Parapiromis nom. nov., a new name for Piromis fennah (Hemiptera: Fulgoromorpha: Ricaniidae), with descriptions of three new species. Zootaxa, 2400: 2940.

Chou, I., Lu, J., Huang, J., Wang, S., 1985. Economic Insects Fauna of China (Fasc. 36) Homoptera: Fulgoroidea. Sciences Press, Beijing, China, pp. 1152.

Copping, L.G., 2004. The Manual of Biocontrol Agents. 3rd Ed., The BioPesticide, British Crop Protection Council, Alton, UK, pp. 702.

Demir, E., 2009. Ricania germar, 1818 species of western palaearctic region (Hemiptera: Fulgoromorpha: Ricaniidae). Munis Entomology and Zoology, 4(1): 271-275.

Deshpande, M.V., 1999. Mycopesticide production by fermentation: Potential and challenges. Journal Critical Reviews in Microbiology, 25(3): 229-243.

Eken, C., Ak, K., Güçlü, Ş., Genç, T., Sekban, R., 2013. Ricania simulans (Hemiptera: Ricaniidae)'in fungal florası. XI. Ulusal Ekoloji ve Çevre Kongresi, 01-04 Ekim, Samsun, Türkiye, s. 208.

Fletcher, M.J., 2008. A key to the genera of Ricaniidae (Hemiptera: Fulgoromorpha) recorded in Australia with notes on the Australian fauna, including a new 
species of Epithalamium Kirkaldy. Australian Journal of Entomology, 47(2):_107-120.

Gjonov, I., 2011. Ricania japonica Melichar, 1898-a representative of family Ricaniidae (Homoptera, Fulgoromorpha), new to the fauna of Bulgaria. ZooNotes, 23: 1-3.

Gnezdilov, V.M., 2009. A new subfamily of the planthopper family Ricaniidae Amyot et Serville (Homoptera, Fulgoroidea). Entomological Review, 89(9): 1082-1086.

Gokturk, T., Tozlu, E., Kotan, R., 2018. Prospects of entomopathogenic bacteria and fungi for biological control of Ricania simulans (Walker 1851) (Hemiptera: Ricaniidae). Pakistan Journal of Zoology, 50(1): 75-82.

Göktürk, T., Aksu Y., 2014. Tarım ve orman alanlarında zarar yapan Ricania simulans (Walker, 1851) (Hemiptera: Ricaniidae)'un morfolojisi, biyolojisi ve zarar1. Türkiye II. Orman Entomolojisi ve Patolojisi Sетроzуити, 7-9 Nisan, Antalya, Türkiye, s. 282285.

Göktürk, T., Mihlı, A., 2015. Doğu Karadeniz sahil șeridinin önemli zararlısı Ricania simulans (Walker,1851) (Hemiptera: Ricaniidae)'ın mücadelesi üzerine araştırmalar. Artvin Çoruh Üniversitesi Orman Fakültesi Dergisi, 16(1): 89-93.

Guclu, S., Ak, K., Eken, C., Akyol, H., Sekban, R., Beytut, B., Yıldırım, R., 2010. Pathogenicity of Lecanicillium muscarium against Ricania simulans. Bulletin of Insectology, 63(2): 243-246.

Gurulingappa, P., McGee, P., Sword, G.A., 2011. In vitro and in planta compatibility of insecticides and the endophytic entomopathogen, Lecanicillium lecanii. Mycopathologia, 172(2): 161-168.

Khachatourians, G.G., Sohail, S.Q., 2008. Entomopathogenic fungi. In: A.A. Brakhage and P.F. Zipfel (Eds.), Biochemistry and Molecular Biology, Human and Animal Relationships, 2nd Edition, The Mycota VI, Springer-Verlag, Berlin, Heidelberg, pp. 33-61.

Kim, J.J., Lee, M.H., Yoon, C.S., Kim, H.S., Yoo, J.K., Kim, K.C., 2001. Control of cotton aphid and greenhouse white with a fungal pathogen. In: Biological control of greenhouse pests, Food \& Fertilizer Technology Center Extension Bulletin 502, Food \& Fertilizer Technology Center, Taipei, Taiwan, pp. 8-15.

Lacey, L.A., Frutos, R., Kaya, H.K., Vail, P., 2001. Insect pathogens as biological control agents: Do they have a future? Biological Control, 21(3): 230-248.

Nast, J., 1987. The Auchenorrhyncha (Homoptera) of
Europe. Annales Zoologici Warszawa, 40(35): 535661.

Oztemiz, S., 2018. Ricania japonica (Hemiptera: ricaniidae): Found in the western Black Sea, Turkey. Munis Entomology and Zoology, 13(1): 326-328.

Roy, H.E., Steinkraus, D.C., Eilenberg, J., Hajek, A.E., Pell, J.K., 2006. Bizarre interactions and endgames: Entomopathogenic fungi and their arthropod hosts. Annual Review of Entomology, 51(1): 331-57.

Sandhu, S.S., Sharma, A.K., Beniwal, V., Goel, G., Batra, P., Kumar, A., Jaglan, S., Sharma, A.K., Malhotra, S., 2012. Myco-biocontrol of insect pests: Factors involved, mechanism, and regulation. Journal of Pathogens, 1-10.

Sezen, K., Feyza, A., Demirbag, Z., 2014. Determination of bacterial control agents of Ricania simulans. 3. International Molecular Biology and Biotechnology Congress, June 02-06, Karadeniz Technical University, Trabzon, Turkey, pp. 159.

Urban, J.M., Cryan, J.R., 2007. Evolution of the planthoppers (Insecta: Hemiptera: Fulgoroidea) Molecular Phylogenetics and Evolution, 42(2): 556572.

Vestergaard, S., Cherry, A., Keller, S., Goettel, M.S. 2003. Safety of hyphomycete fungi as microbial control agents. In: H.M.T. Hokkanen and A.E. Hajek (Eds.), Environmental Impacts of Microbial Insecticides, Kluwer Academic Publishers, Dordrecht, pp. 35-62.

Wojciechowska, M., Stepnowski, P., Gołębiowski, M., 2016. The use of insecticides to control insect pests. Invertebrate Survival Journal, 13(1): 210-220.

Wraight, S.P., Jackson, M.A., Kock, S.L., 2001 Production, stabilization and formulation of fungal biocontrol agents. In: T.M. Butt, C. Jackson and N. Magan (Eds.), Fungi as biocontrol agents: Progress problems and potential, CABI Publishing, pp. 253287.

Xu, C.Q., Liang, A.P., Jiang, G.M., 2006. The genus Euricania Melichar (Hemiptera: Ricaniidae) from China. The Raffles Bulletin of Zoology, 54(1): 1-10.

Yıldız, Y., Yıldırım, İ., Bostanc1, C., 2018. Bartın ilinin istilacı böcek türleri. III. Türkiye Orman Entomolojisi ve Patolojisi Sempozyumu, 10-12 May1s, Artvin, Türkiye, s. 25.

Zimmermann, G., 2008. The entomopathogenic fungi Isaria farinosa (formerly Paecilomyces farinosus) and the Isaria fumosorosea species complex (formerly Paecilomyces fumosoroseus)'. biology, ecology and use in biological control. Biocontrol Science and Technology, 18(9): 865-901. 